\title{
Area of concern: A new paradigm in life cycle assessment for the development of footprint metrics
}

\section{Journal Article}

\section{Author(s):}

Ridoutt, Bradley G.; Pfister, Stephan (D); Manzardo, Alessandro; Bare, Jane; Boulay, Anne-Marie; Cherubini, Francesco; Fantke, Peter; Frischknecht, Rolf (D); Hauschild, Michael; Henderson, Andrew; Jolliet, Olivier; Levasseur, Annie; Margni, Manuele; Mckone, Thomas; Michelsen, Ottar; Canals, Llorenç M.I.; Page, Girija; Pant, Rana; Raugei, Marco; Sala, Serenella; Verones, Francesca

\section{Publication date:}

2016-02

\section{Permanent link:}

https://doi.org/10.3929/ethz-b-000109289

\section{Rights / license:}

In Copyright - Non-Commercial Use Permitted

\section{Originally published in:}

The International Journal of Life Cycle Assessment 21(2), https://doi.org/10.1007/s11367-015-1011-7 
This is a post-peer-review, pre-copyedit version of an article published in The International Journal of Life Cycle Assessment. The final authenticated version is available online at: http://dx.doi.org/10.1007/s11367-015-1011-7.

UNEP/SETAC CORNER

\section{Area of Concern: A new paradigm in life cycle assessment for the}

\section{8 development of footprint metrics}

9 Bradley Ridoutt • Stephan Pfister • Alessandro Manzardo • Jane Bare • Anne-Marie Boulay • Francesco Cherubini •

10 Peter Fantke $•$ Rolf Frischknecht • Michael Hauschild • Andrew Henderson • Olivier Jolliet • Annie Levasseur •

11 Manuele Margni • Thomas McKone • Ottar Michelsen • Llorenç Milà i Canals • Girija Page • Rana Pant • Marco

Raugei $\bullet$ Serenella Sala $\bullet$ Francesca Verones

B.G. Ridoutt $(\bowtie)$

Commonwealth Scientific and Industrial Research Organisation (CSIRO), Private Bag 10, Clayton South, Victoria

Africa

e-mail: brad.ridoutt@csiro.au

Tel: +61395452159

Fax: +61 395452314

Stephan Pfister

ETH Zurich, Institute of Environmental Engineering, 8093 Zurich, Switzerland

Alessandro Manzardo

Università degli Studi di Padova, Dipartimento Ingegneria Industriale, Centro Studi Qualità Ambiente, Padova

Jane Bare $•$ Andrew Henderson

United States Environmental Protection Agency, Sustainable Technology Division, Systems Analysis Branch,

31 National Risk Management Research Laboratory, Cincinnati, OH 45268, USA

32 Anne-Marie Boulay • Annie Levasseur • Manuele Margni

33 CIRAIG, Polytechnique Montreal, Montreal, Canada 
35 Norwegian University of Science and Technology (NTNU), Industrial Ecology Programme, Department of Energy and Process Engineering, NO-7491 Trondheim, Norway

Peter Fantke • Michael Hauschild

Technical University of Denmark (DTU), Department of Management Engineering, Division for Quantitative

Rolf Frischknecht

treeze Ltd., Uster, Switzerland

Olivier Jolliet

Ottar Michelsen

NTNU Sustainability, Norwegian University of Science and Technology, NO-7491 Trondheim, Norway

Llorenç Milà i Canals

United Nations Environment Programme (UNEP), Division for Technology, Industry and Economics, 15 Rue de Milan, 75009 Paris, France

Girija Page

University of Western Sydney, School of Science and Health, Penrith, NSW 2751, Australia

Rana Pant $\bullet$ Serenella Sala

61 European Commission, Joint Research Centre, Institute for Environment and Sustainability, Via Enrico Fermi 2749, 62 Ispra, I-21027, Italy

63

64 Marco Raugei

65 Oxford Brookes University, Department of Mechanical Engineering and Mathematical Sciences, Oxford OX33 1HX,

66 United Kingdom 
Purpose As a class of environmental metrics, footprints have been poorly defined, have shared an unclear relationship to Life Cycle Assessment (LCA), and the variety of approaches to quantification have sometimes resulted in confusing and contradictory messages in the marketplace. In response, a task force operating under the auspices of the UNEP/SETAC Life Cycle Initiative project on environmental Life Cycle Impact Assessment (LCIA) has been working to develop generic guidance for developers of footprint metrics. The purpose of this paper is to introduce a universal footprint definition and related terminology as well as to discuss modelling implications.

Methods The task force has worked from the perspective that footprints should be underpinned by the same data systems and models as used in LCA. However, there are important differences in purpose and orientation relative to LCA impact category indicators. Footprints have a primary orientation toward society and nontechnical stakeholders. They are also typically of narrow scope, having the purpose of reporting only in relation to specific topics. In comparison, LCA has a primary orientation toward stakeholders interested in comprehensive evaluation of overall environmental performance and trade-offs among impact categories. These differences create tension between footprints, the existing LCIA framework based on the Area of Protection paradigm, and the core LCA standards ISO14040/44. Results In parallel to Area of Protection, we introduce Area of Concern as the basis for a universal footprint definition. In the same way that LCA uses impact category indicators to assess impacts that follow a common cause-effect pathway toward Areas of Protection, footprint metrics address Areas of Concern. The critical difference is that Areas of Concern are defined by the interests of stakeholders in society rather than the LCA community. In addition, Areas of Concern are stand-alone and not necessarily part of a framework intended for comprehensive environmental performance assessment. The Area of Concern paradigm is needed to support the development of footprints in a way that fulfils their distinctly different purpose. It is also needed as a mechanism to extricate footprints from some of the provisions of ISO 14040/44 which are not considered relevant. Specific issues are identified in relation to double counting, aggregation, and the selection of relevant indicators. foundation that will support the development of footprint metrics in parallel with LCA. 
97 Keywords Area of protection • environmental footprint $\bullet$ environmental labels and declarations $\bullet$ footprint 98 definition • footprint indicator • ISO $14044 \cdot$ life cycle impact assessment $•$ UNEP/SETAC Life Cycle 99 Initiative 
102 Over recent years, footprints have emerged as an important means of reporting environmental

103 performance. However, as a class of environmental metrics they have been poorly defined, have shared an unclear relationship to Life Cycle Assessment (LCA), and have been the subject of numerous approaches to quantification which have sometimes led to confusing and contradictory messages in the marketplace (Fang and Heijungs 2015; Lenzen 2013; Ridoutt and Pfister 2013). In response, the UNEP/SETAC Life Cycle Initiative (see www.lifecycleinitiative.org) Phase 3 project on environmental Life Cycle Impact Assessment (LCIA) (Jolliet et al. 2014) has established a task force on footprints. The purpose of the task force is to propose a universal footprint definition and provide generic guidance for developers of footprint metrics. The International Organization for Standardization (ISO) has recently published documents specifically concerning product carbon footprints (ISO/TS14067 2013) and water footprints (ISO14046 2014). However, the variety of footprint metrics is expanding rapidly and generic guidance is urgently needed. between footprints and existing LCA impact category indicators (Ridoutt et al. 2015). In short, footprints are deemed to have a primary orientation toward society and nontechnical stakeholders and report on only selected topics of concern. On the other hand, LCA impact category indicators report in relation to a larger framework (Jolliet et al. 2004) and have a primary orientation toward stakeholders interested in comprehensive evaluation of environmental performance and trade-offs. The task force also identified four attributes that should characterise all footprint metrics: environmental relevance, accurate terminology, directional consistency and transparent documentation. In addition, it was recognised that footprints might be based on life cycle inventory data (provided the environmental relevance criterion is satisfied), an existing LCA impact category indicator result, or the combination of results from different LCA impact categories of relevance to the topic of the footprint (see Ridoutt et al. 2015 for further detail and examples). underpinned by the same data systems and models in order to achieve efficiency of calculation and consistency of results. To avoid confusion and contradiction, it is considered important that a footprint 
example, a water footprint should provide results which are consistent with the subset of LCA impact

131 category indicator results concerning water. However, the differences in purpose and orientation mean

132 that the existing LCA framework (Jolliet et al. 2004) and core LCA standards (ISO14040 2006,

133 ISO14044 2006) may not be directly applicable to footprint metrics. The purpose of this paper is to

134 propose a universal footprint definition and related terminology that have arisen from the work of the task

135 force. In addition, the paper discusses some modelling implications which are peculiar to footprint

136 metrics and which may deviate from conventional LCA practices at some points.

\section{2. Universal footprint definition}

138 The overall architecture of life cycle impact assessment involves relating life cycle inventory results to

139 impact category indicators which are located along environmental mechanisms which ultimately address

140 Areas of Protection - also referred to as safeguard subjects (Jolliet et al. 2004). Human health, natural

141 environment and natural resources are three commonly defined Areas of Protection (Finnveden et al.

142 2009), although there is no absolute agreement about the number of Areas of Protection or how they

143 should be individually defined, and the subject has been richly debated over the years (Hertwich and

144 Hammitt 2001, Klöpffer 2002, Bare and Gloria 2008, Dewulf et al. 2015). The LCIA framework is

145 important as the basis for classifying (ISO14044 Section 4.4.2.3) and characterising (ISO14044 Section

146 4.4.2.4) emissions and resource use data, as well as for undertaking any of the optional steps of

147 normalising, grouping and weighting (ISO14044 Section 4.4.3). The framework facilitates, insofar as

148 scientific knowledge and the state of characterisation models allow, a comprehensive evaluation of

149 environmental issues for the product or system under study. However, as mentioned previously (Ridoutt

150 et al. 2015), the LCIA framework, defined by the LCA community and designed for comprehensive and

151 systematic evaluation of environmental performance, does not necessarily correspond with the lenses

152 through which society perceives environmental protection, which tend to be more topical and less

153 holistic.

154 In parallel with Area of Protection, we therefore define Area of Concern as a basis for a

155 universal footprint definition (Table 1). In the same way that LCA impact category indicators address one

156 or more Areas of Protection, footprint metrics address an Area of Concern. For example, a carbon

157 footprint responds to societal concern about global warming, and the water footprint responds to societal

158 concern about the over-exploitation and degradation of water resources. A critical difference is that Areas 
of Concern are stand-alone and not necessarily part of a framework intended for comprehensive environmental performance evaluation. They are also defined by the interests of stakeholders in society rather than the LCA community. We perceive this to be the primary explanation for the growing awareness of and interest in footprints in society. As members of society become informed about environmental problems, through the wide ranging activities of scientists and science communicators and even first-hand experience, there is an associated interest in information about how products (and organisations, see ISO14072 2014; UNEP 2015) contribute to these problems. Footprint metrics provide this information, based on the life cycle perspective. In this context, the term society is considered broadly, and includes government and non-governmental organisations and business entities as agents reflecting societal interests. Product footprinting programmes initiated by governments or business organisations are an expression of this. with a package of environmental constructs which may be excellently devised for comprehensive environmental assessment, but poorly aligned with the environmental issues as conceptualised by nontechnical stakeholders - tantamount to speaking in a language the wider society fails to appreciate, however rich and wonderful that language may itself be. In addition, the Area of Concern paradigm is needed because the LCIA framework and the requirements of ISO14040/44 were not designed for the development of footprints as will be explained in the following section.

\section{3. Modelling implications}

178 3.1. Double counting

179 In LCA, emphasis is placed on avoiding double counting. This is consistent with the intention of comprehensively evaluating environmental performance and trade-offs. To double count resource use or emissions in the inventory phase or to double count the same environmental impacts in overlapping impact category indicators would clearly bias the evaluation. According to ISO14044 (Section 4.4.2.2.3), “...impact categories, category indicators and characterisation models should avoid double counting." Stronger language is used in ISO14046 (Section 6.1) where, "Redundant impact category indicators (i.e. indicators containing double counting) shall not be reported in parallel without clear indication of redundancy.” The ILCD Handbook (EC JRC 2010, p. 110) uses similarly strong language, requiring that 
In the case of individual footprints, potential impacts relating to an Area of Concern need to be assessed completely and also without double-counting. For example, in regard to product carbon footprints, ISO/TS14067 (Section 5.12) includes as a principle the, "Avoidance of double counting." Greenhouse gas emissions and removals should not be counted more than once and particular attention is drawn to the need to avoid double counting of renewable energy sources in certified electrical supply products as well as national grid electricity mixes.

However, the situation is anticipated whereby the same environmental impacts are included in different footprints and a situation of double counting would occur if these footprints were presented together in a footprint profile (see definition in Table 1). For example, a water footprint and a chemical footprint might both include impacts related to chemical emissions to water. With footprint profiles, potential overlapping is allowable because the priority is for each stand-alone footprint to address its Area of Concern completely thereby making possible the comparison of individual footprints between products. If, for a particular product, the impacts related to chemical emissions to water were excluded from the water footprint (because those impacts were already counted in the chemical footprint), the resultant water footprint would no-longer be complete and could no-longer be simply compared to the water footprint of another product.

In LCIA, the objective is comprehensive evaluation of environmental performance and tradeoffs, double counting is therefore avoided, and impact categories, category indicators and characterization models are chosen accordingly. Modelling choices are explained in a technical LCA study report. The Area of Concern paradigm is needed because footprints differ in all these respects. Footprints are defined by the interests of society. If a water footprint and chemical footprint are presented, it is because there is demand for reporting on both these environmental topics, not because these two footprints are intended to represent all of the relevant environmental impacts. Double counting of impacts in overlapping footprints is not something to be avoided, but an acknowledged possibility when priority is given to each stand-

212 alone footprint addressing its Area of Concern completely. In addition, footprints, with their orientation toward society and nontechnical stakeholders, need to be understandable without reference to technical

214 study reports. Technical reports are required, but for review by technical experts and other interested parties having access to technical skills, not for the primary audience of stakeholders in society for whom no assumptions are made about their interest to consult or ability to understand technical documentation. 
218 Certain Areas of Concern can be addressed by a footprint that corresponds with an existing indicator used

219 in LCA. A carbon footprint is one such example; a freshwater eutrophication footprint is another.

220 However, other Areas of Concern cannot be readily addressed in this way because there are multiple relevant environmental mechanisms and no single LCA inventory or impact category indicator is sufficient. For example a water footprint might include multiple environmental mechanisms relating to water consumption and water degradation (which might involve different Areas of Protection). According to ISO14044 (Section 4.4.3.1), normalisation, grouping and weighting are optional elements and are restricted in some contexts (e.g. comparative assertions). In the context of footprints, it is acknowledged that these steps may sometimes be necessary if there is societal demand for one single metric addressing a complex Area of Concern (e.g. the abovementioned water footprint case). At this point another potential conflict with ISO14044 (2006) could arise depending on how Section 4.4.3.4.3 is interpreted. "Data and indicator results or normalised indicator results reached prior to weighting should be made available together with the weighted results." If together is interpreted to mean at the same point and time where a footprint is communicated (such as a product label), the group does acknowledge the potential challenge in practicality. That said, the task force did consider it essential that aggregation methods and calculations used in footprinting are documented transparently and made publicly available.

The steps involved in creating aggregated footprints introduce additional modelling choices and there is the potential that these steps could result in footprints which are misleading. As such, organisations intending to operate footprint programmes are advised to give close attention to this subject in defining acceptable methods and documentation requirements. The new international standard concerning footprint communications (ISO14026, in development) is another opportunity to develop appropriate safeguards. In the Task Group's ongoing work, further discussions about additional guidance on the use of weighting in footprints will be a high priority.

241 3.3. Selection of relevant indicators

242 The specific details of the goal and scope can vary from one LCA study to another. However, the general intent is the identification of significant environmental issues (ISO14044 Section 4.5.2). As such, the selection of relevant impact categories is an important step and, “...shall reflect a comprehensive set of environmental issues related to the product system being studied..." (Section 4.4.2.2). Similarly, in the development of Type III environmental labels (e.g. environmental product declarations), the selection of criteria to report must, in so far as possible, reflect environmental criteria that are important to the product 
249 products based on the most relevant environmental aspects. In contrast, an individual footprint reports 250 only in relation to a specific Area of Concern, in response to societal interest in that Area of Concern.

251 From a societal point of view, it is relevant to know about a footprint result regardless of whether it is 252 large or small. As such, a footprint addressing a particular Area of Concern does not imply that this is a significant issue for that product life cycle. For example, a retailer might perceive that their customers are concerned about climate change and in response require all product suppliers to participate in a product carbon footprint programme. That said, it is also envisaged that operators of footprint programmes might stipulate particular footprint profiles appropriate to different product categories as a way of highlighting the priority environmental issues.

\section{Final thoughts}

Ideally, footprints should develop in parallel with LCA: in close relationship, but each with its own

260 primary orientation and purpose. This will require the development of new guidance documentation for footprints as there are elements of the core LCA standards (ISO14040 2006, ISO14044 2006) that are not directly applicable. This is not surprising since ISO14040/44 predate the more recent popular interest in footprints and say nothing about them. In any case, the scientific rigour and the consensus building underlying current LCIA methods represent a strong asset which should be utilized to the extent possible when developing footprint indicators. The universal footprint definition and related terminology introduced in this paper are a next step in building a foundation to support the development of footprints in parallel with LCA. In the meantime, the task force continues its work and will report as further guidance is developed.

Acknowledgements and disclaimer This work is supported by the United Nations Environment Programme (UNEP) / Society of Environmental Toxicology and Chemistry (SETAC) Life Cycle Initiative. Public and private sector sponsors are listed on the Initiative's website (http://www.lifecycleinitiative.org/). The views expressed in this article are those of the authors and do not necessarily reflect those of the various affiliated organizations. 
Bare JC, Gloria TP (2008) Environmental impact assessment taxonomy providing comprehensive coverage of midpoints, endpoints, damages, and areas of protection. J Clean Prod 16(10):10211035.

Dewulf J, Benini L, Mancini L, Sala S, Blengini GA, Ardente F, Recchioni M, Maes J, Pant R, Pennington D (2015) Rethinking the area of protection "Natural Resources" in life cycle assessment. Environ Sci Technol 49(9):5310-5317.

EC JRC [European Commission, Joint Research Centre] (2010) International Reference Life Cycle Data System (ILCD) Handbook - General Guide for Life Cycle Assessment - Detailed Guidance. Publications Office of the European Union, Luxembourg.

Fang K, Heijungs R (2015) Rethinking the relationship between footprints and LCA. Environ Sci Technol 49(1):10-11.

Finnveden G, Hauschild MZ, Ekvall T, Guinée J, Heijungs R, Hellweg S, Koehler A, Pennington D, Suh S (2009) Recent developments in life cycle assessment. J Environ Manage 91(1):1-21.

Hertwich EG, Hammitt JK (2001) A decision-analytic framework for impact assessment part I: LCA and decision analysis. Int J Life Cycle Assess 6(1):5-12.

ISO 14025 (2006) Environmental labels and declarations - Type III environmental declarations Principles and procedures. International Organization for Standardization, Geneva.

ISO 14040 (2006) Environmental management - Life cycle assessment - Principles and framework. International Organization for Standardization, Geneva.

ISO 14044 (2006) Environmental management - Life cycle assessment - Requirements and guidelines. International Organization for Standardization, Geneva.

ISO 14046 (2014) Environmental management - Water footprint - Principles, requirements and guidelines. International Organization for Standardization, Geneva.

ISO/TS 14067 (2013) Greenhouse gases - Carbon footprint of products - Requirements and guidelines for quantification and communication. International Organization for Standardization, Geneva.

ISO/TS 14072 (2014) Environmental management - Life cycle assessment - Requirements and guidelines for organizational life cycle assessment. International Organization for Standardization, Geneva.

Jolliet O, Frischknecht R, Bare J, Boulay AM, Bulle C, Fantke P, Gheewala S, Hauschild M, Itsubo N, 

guidance on environmental life cycle impact assessment indicators: findings of the scoping phase. Int J Life Cycle Assess 19(4):962-967.

Jolliet O, Müller-Wenk R, Bare J, Brent A, Goedkoop M, Heijungs R, Itsubo N, Peña C, Pennington D, Potting J, Rebitzer G, Stewart M, Udo de Haes H, Weidema B (2004) The LCIA midpointdamage framework of the UNEP/SETAC Life Cycle Initiative. Int J Life Cycle Assess 9(6):394404.

314 Klöpffer W (2002) The area of protection debate. Int J Life Cycle Assess 7(2):94.

315 Lenzen M (2013) An outlook into a possible future of footprint research. J Ind Ecol 18(1):4-6.

316 Ridoutt B, Fantke P, Pfister S, Bare J, Boulay AM, Cherubini F, Frischknecht R, Hauschild M, Hellweg S, Henderson A, Jolliet O, Levasseur A, Margni M, McKone T, Michelsen O, Milà i Canals L, Page G, Pant R, Raugei M, Sala S, Saouter E, Verones F, Wiedmann T (2015) Making sense of the minefield of footprint indicators. Environ Sci Technol 49(5):2601-2603.

Ridoutt BG, Pfister S (2013) Towards an integrated family of footprint indicators. J Ind Ecol 17(3):337339.

UNEP (2015). Guidance on Organizational Life Cycle Assessment. UNEP/SETAC Life Cycle Initiative, TU Berlin and Kogakuin University, Paris. 
Table 1 Terms and definitions

\begin{tabular}{ll}
\hline Term & \multicolumn{1}{c}{ Definition } \\
\hline Footprint & $\begin{array}{l}\text { Metric used to report life cycle assessment } \\
\text { results addressing an Area of Concern }\end{array}$ \\
Area of Concern & $\begin{array}{l}\text { Environmental topic defined by the interest } \\
\text { of society }\end{array}$ \\
Footprint profile & $\begin{array}{l}\text { A list of footprints addressing different } \\
\text { Areas of Concern }\end{array}$ \\
\hline
\end{tabular}

329 